\title{
Esophageal adenocarcinoma on esophageal varices - endoscopic resection after transjugular intrahepatic portosystemic shunt
}

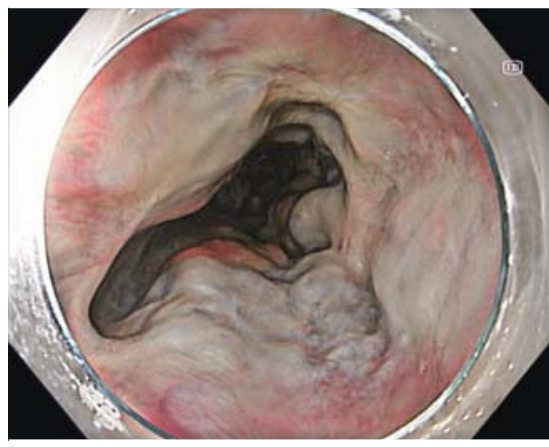

- Fig. 1 Esophageal adenocarcinoma on esophageal varices and scars after variceal band ligation.

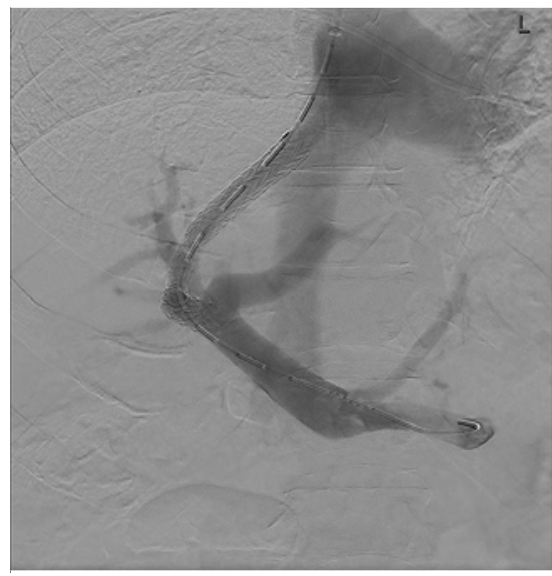

- Fig. 2 Implantation of transjugular intrahepatic portosystemic shunt.

Endoscopic resection is the first-choice therapy for T1a esophageal adenocarcinoma (EAC) [1]. In patients with liver cirrhosis, endoscopic resection might be difficult due to portal hypertension, esophageal varices, and coagulation disorders. Few case reports describe endoscopic resection in this setting and the optimal treatment strategy is not defined [2-5].

We report on a 56-year-old man who was referred for endoscopic resection of EAC arising within Barrett's esophagus. Alcoholic liver cirrhosis had been diagnosed 6

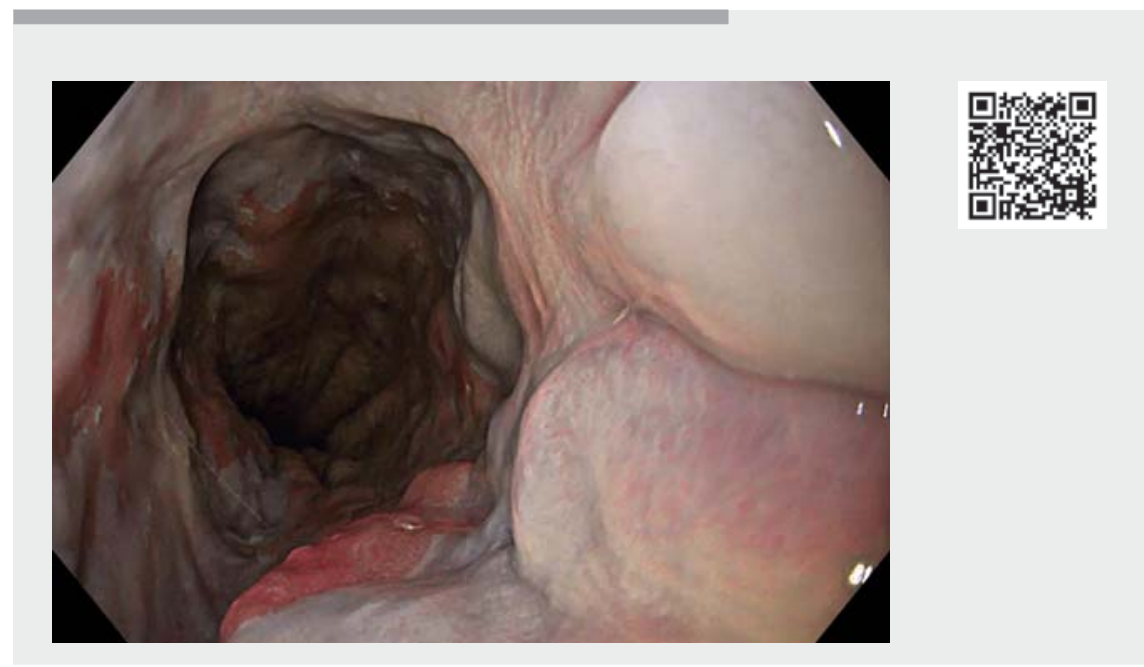

$\triangle$ Video 1 Esophageal adenocarcinoma on esophageal varices and scars after variceal band ligation. Prior to endoscopic submucosal dissection, transjugular intrahepatic portosystemic shunt implantation was performed to reduce the intravariceal pressure and the bleeding risk.

months earlier after severe bleeding from esophageal varices. The bleeding was stopped with variceal band ligation and the patient stopped drinking. During a scheduled follow-up endoscopy 3 months later, variceal band ligation was repeated and Barrett's esophagus was diagnosed. Biopsies from a slightly elevated lesion revealed low-grade dysplasia.

In our hospital the patient presented in good clinical condition with compensated liver cirrhosis (Child-Pugh class A, bilirubin $2.5 \mathrm{mg} / \mathrm{dl}$, platelet count $49 / \mathrm{nl}$, INR 1.2, absence of ascites and encephalopathy). Esophagogastroduodenoscopy (EGD) showed Barrett's esophagus $\mathrm{C} 1 \mathrm{M} 3$ with two neoplastic areas and persistence of esophageal varices beneath multiple scars after variceal band ligation ( $\triangleright$ Fig. 1, $\triangleright$ Video 1). The bleeding risk of endoscopic resection seemed inacceptable. Transjugular intrahepatic portosystemic shunt (TIPS) placement was performed including radiologic emboli- zation of the left gastric vein ( $>$ Fig. 2 , - Fig.3). The hepatic venous pressure gradient was reduced from $19 \mathrm{~mm} \mathrm{Hg}$ to $9 \mathrm{~mm} \mathrm{Hg}$.

Transabdominal ultrasound 6 weeks later confirmed patency of the TIPS. Endoscopy showed regredience of the esophageal varices and end endoscopic submucosal dissection (ESD) was performed under general anesthesia ( $\triangleright$ Video 1 ). Repeated bleeding during ESD was controlled endoscopically and terlipressin was administered for 24 hours. After an uneventful course, the patient was discharged 72 hours after ESD. Histology showed curative resection of two mucosal EACs ( $\triangleright$ Fig. 4 ).

TIPS implantation followed by endoscopic resection is a promising strategy in the treatment of early esophageal neoplasia in patients with esophageal varices.

Endoscopy_UCTN_Code_CCL_1AB_2AC_3AB 


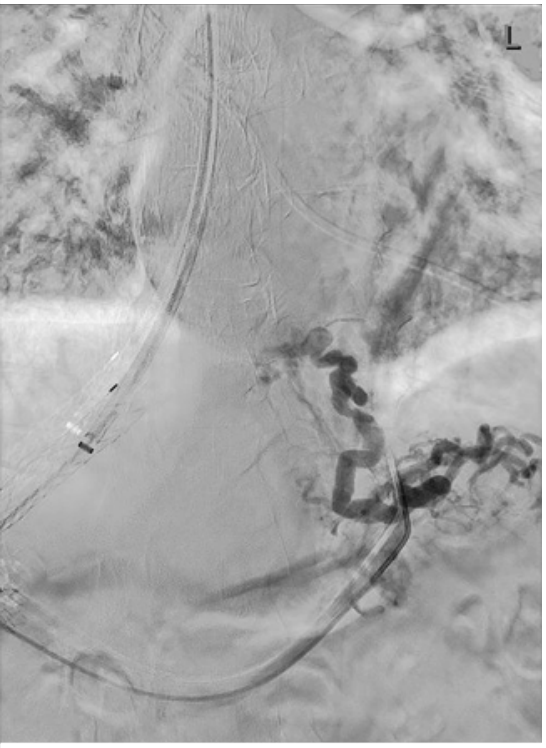

- Fig. 3 Embolization of the left gastric vein.

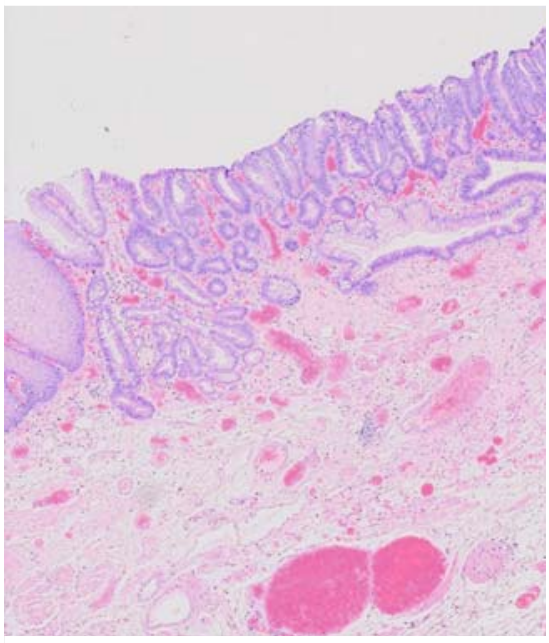

Fig. 4 Histopathology of the endoscopic submucosal dissection resection specimen showing well-differentiated intramucosal esophageal adenocarcinoma and multiple dilated vessels in the submucosal layer.

\section{Competing interests}

The authors declare that they have no conflict of interest.

\section{The authors}

\section{Andreas Probst ${ }^{1}$, Christian Scheurig-}

Münkler ${ }^{2}$, Stefan Gölder ${ }^{1}$, Bei Huang ${ }^{3}$, Helmut Messmann', Georg Braun'

1 Department of Gastroenterology, University Hospital Augsburg, Augsburg, Germany

2 Department of Diagnostic and Interventional Radiology, University Hospital Augsburg, Augsburg, Germany

3 Institute of Pathology, University Hospital Augsburg, Augsburg, Germany

\section{Corresponding author}

\section{Andreas Probst, MD}

Department of Gastroenterology, University Hospital Augsburg,

Stenglinstrasse 2, 86156 Augsburg,

\section{Germany}

Fax: +49-821-400-3331

andreas.probst@uk-augsburg.de

\section{References}

[1] Weusten B, Bisschops R, Coron E et al Endoscopic management of Barrett's esophagus: European Society of Gastrointestinal Endoscopy (ESGE) Position Statement. Endoscopy 2017; 49: 191-198

[2] Sawaguchi M, Jin M, Matsuhashi T et al. The feasibility of endoscopic submucosal dissection for superficial esophageal cancer in patients with cirrhosis (with video). Gastrointest Endosc 2014; 79: 681-685

[3] Mohapatra S, Montgomery E, Kohli R et al. Endoscopic submucosal dissection for Barrett's-associated adenocarcinoma in a patient with decompensated cirrhosis and esophageal varices. VideoGIE 2020; 5: 190 192
[4] NeSmith M, Jou J, Fennerty B et al. Transjugular intrahepatic portosystemic shunt prior to endoscopic mucosal resection for Barrett's esophagus in the setting of varices. ACG Case Rep 2014; 1: 189-192

[5] Ueda C, Yosizaki T, Katayama N et al. Barrett's adenocarcinoma with esophageal varices successfully treated by endoscopic submucosal dissection with direct varices coagulation. Clin J Gastroenterol 2020; 13: 178-181

\section{Bibliography}

Endoscopy 2022; 54: E7-E8

DOI 10.1055/a-1346-8473

ISSN 0013-726X

published online 16.2 .2021

(c) 2021. Thieme. All rights reserved.

Georg Thieme Verlag KG, Rüdigerstraße 14, 70469 Stuttgart, Germany

\section{ENDOSCOPY E-VIDEOS \\ https://eref.thieme.de/e-videos}

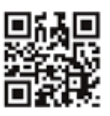

Endoscopy E-Videos is a free access online section, reporting on interesting cases and new techniques in gastroenterological endoscopy. All papers include a high quality video and all contributions are freely accessible online.

This section has its own submission website at https://mc.manuscriptcentral.com/e-videos 